\title{
Muscarinic Receptors in Perirhinal Cortex Control Trace Conditioning
}

\author{
Sun Jung Bang ${ }^{1}$ and Thomas H. Brown ${ }^{1,2}$ \\ Departments of ${ }^{1}$ Psychology and ${ }^{2}$ Cellular and Molecular Physiology, Yale University, New Haven, Connecticut 06520
}

Trace conditioning requires that a transient representation of the conditional stimulus (CS) persists during the time interval between the CS offset and the onset of the unconditional stimulus. According to one hypothesis, this transient CS representation is supported by endogenous activity in "persistent-firing" neurons of perirhinal cortex (PR). By definition, persistent-firing neurons discharge for tens of seconds or minutes after the termination of the original spike-initiating stimulus. This continued spiking does not depend on recurrent circuit activity and can be reliably and completely blocked by muscarinic receptor antagonists. The present study evaluated the role of PR muscarinic receptors in trace fear conditioning. Before conditioning, rats received bilateral intra-PR infusions with either saline or scopolamine, a nonselective muscarinic receptor antagonist. Scopolamine infusions profoundly impaired trace conditioning but had no effect on delay conditioning or context conditioning. The results encourage a more general understanding of muscarinic receptors in PR and they motivate additional tests of the emerging theory that persistent-firing neurons support aspects of transient memory.

\section{Introduction}

Damage to perirhinal cortex (PR) profoundly impairs three types or aspects of fear conditioning: context conditioning (Bucci et al., 2000; Lindquist et al., 2004; Kholodar-Smith et al., 2008a,b; Bang and Brown, 2009); delay conditioning to discontinuous, but not continuous, auditory cues (Lindquist et al., 2004; KholodarSmith et al., 2008a; Bang and Brown, 2009); and trace conditioning (Kholodar-Smith et al., 2008b). To create a general theory of the role of PR in acquired fear, we need to know whether and how these three major deficits can be dissociated. Here, we attempted to isolate the role of PR in trace conditioning.

Trace conditioning requires that a transient representation of the conditional stimulus (CS) persists from the CS offset to the onset of the unconditional stimulus (US) (Thompson, 2005; Woodruff-Pak and Disterhoft, 2008). One recent hypothesis proposes that trace fear conditioning is supported by activity in "persistent-firing" (PF) neurons in PR (Leung et al., 2006; Kholodar-Smith et al., 2008b) (cf. Hasselmo et al., 2007). By definition, PF neurons discharge for tens of seconds to several minutes after the termination of the original excitatory stimulus. PF neurons are abundant in entorhinal cortex (EC) (Egorov et al., 2002; Fransén et al., 2006; Reboreda et al., 2007; Tahvildari et al., 2007,2008 ), the lateral nucleus of the amygdala (LA) (Egorov et al., 2006), and PR (Leung et al., 2006). Computational models have been elucidating how transient memory can be represented by the collective activity of PF neurons (Fransén et al., 2002; Hasselmo and Stern, 2006; Hasselmo, 2008).

Persistent firing is supported by a $\mathrm{Ca}^{2+}$-activated, nonspe-

Received Jan. 6, 2009; revised Feb. 17, 2009; accepted March 4, 2009.

This work was supported by National Institutes of Health Research Grant MH058405 and Yale University.

Correspondence should be addressed to Thomas H. Brown, Department of Psychology, Yale University, 2 Hillhouse Avenue, New Haven, CT 06520. E-mail: thomas.brown@yale.edu.

D01:10.1523/JNEUROSCI.0069-09.2009

Copyright $\odot 2009$ Society for Neuroscience $\quad$ 0270-6474/09/294346-05\$15.00/0 cific, cation current $\left(I_{\mathrm{CAN}}\right)$. The conductance increase depends jointly on elevated intracellular $\mathrm{Ca}^{2+}$ levels and activation of muscarinic acetylcholine receptors (mAChRs) (Egorov et al., 2002, 2006; Fransén et al., 2006; Leung et al., 2006; Tahvildari et al., 2008). Persistent firing can be reliably and completely blocked by $\mathrm{mAChR}$ antagonists (Egorov et al., 2002, 2006; Leung et al., 2006). An intriguing relationship has been discovered in humans between mAChR-dependent activity in PR and working memory performance. Functional magnetic resonance imaging disclosed a sustained response in PR during a delayed matching-to-sample task (Schon et al., 2005), a task that is known to depend on PR function (Murray et al., 2007). The sustained response was reduced by systemic injection of a mAChR antagonist, which also resulted in performance deficits (Schon et al., 2005).

Based on the preceding considerations, the present study quantified the effect of blocking mAChRs in rat PR on trace, delay, and context conditioning. Animals received intra-PR infusions with saline or scopolamine, a nonselective $\mathrm{mAChR}$ antagonist, just before trace or delay fear conditioning. Cue- and context-elicited freezing were measured on the following $2 \mathrm{~d}$. Scopolamine infusions profoundly impaired trace cue conditioning but had no effect on context conditioning or delay conditioning to continuous or discontinuous auditory cues.

\section{Materials and Methods}

Subjects. Seventy-five male Sprague Dawley rats (250-350 g; Charles River Laboratories) were individually housed, maintained on a $12 \mathrm{~h} \mathrm{light/}$ dark cycle, given ad libitum access to food and water, and handled for 3-5 $\mathrm{d}$ before surgery. Experiments were in strict compliance with the Institutional Animal Care and Use Committee guidelines of Yale University.

Experimental design. The experimental design included one withinsubjects factor and two between-subjects factors. The within-subjects factor was the time course of freezing behavior during testing. The between-subject factors included the type of PR infusion (scopolamine vs saline) and the type of fear conditioning procedure (Fig. 1). The latter included trace conditioning to a continuous tone, long-delay condition- 
(A) Short-Delay Tone (ISI: $14.6 \mathrm{~s}$ )

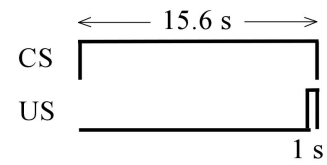

(B) Short-Delay Pips (ISI: $14.6 \mathrm{~s}$ )

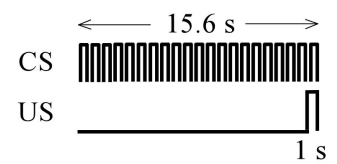

(C) Long-Delay Tone (ISI: $26 \mathrm{~s}$ )

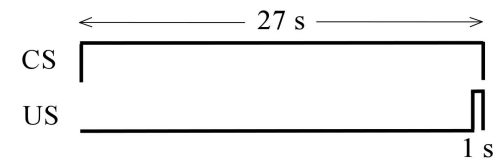

(D) Trace Tone (ISI: $26 \mathrm{~s}$ )

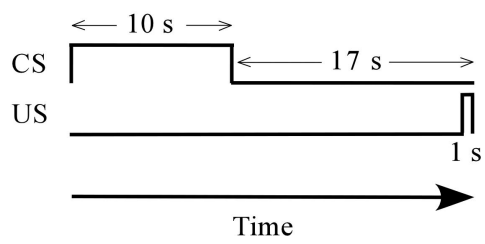

Figure 1. Essential differences among the four fear conditioning groups. $A$, Short-delay conditioning to a continuous tone. B, Short-delay conditioning to a sequence of tone "pips." In both short-delay groups, the CS lasted $15.6 \mathrm{~s}$, and the ISI from the CS onset to the US onset waS 14.6s. C, Long-delay conditioning to a 27 s continuous tone. $\boldsymbol{D}$, Trace conditioning to a 10 s tone. As in the long-delay group, the ISI was $26 \mathrm{~s}$.

ing to a continuous tone, short-delay conditioning to a continuous tone, and short-delay conditioning to a discontinuous tone (termed tone "pips"). All four groups were tested for both cue and context conditioning. The specific contrasts of interest were between scopolamine-infused and saline-infused rats within each of the four conditioning paradigms.

Stimuli and stimulus relationships. Figure 1 illustrates the four auditory CSs and shows their relationships to the somatosensory US. In all four conditioning groups, the US was a $1 \mathrm{~s}$ footshock $(1.3 \mathrm{~mA})$. The four CSs were matched in terms of frequency $(20 \mathrm{kHz})$, loudness $(70 \mathrm{~dB}$ sound pressure level), and rise/fall times $(10 \mathrm{~ms})$. In the trace conditioning group, a $16 \mathrm{~s}$ trace interval separated the offset of the $10 \mathrm{~s}$ CS from the US onset (Fig. 1). The interstimulus interval (ISI) between the CS onset and the US onset was $26 \mathrm{~s}$. These values were based on the study by KholodarSmith et al. (2008b), who found that PR damage profoundly impairs trace conditioning. The long-delay group served as an ISI control to distinguish between effects of the trace interval and effects of the ISI (Beylin et al., 2001; Moyer and Brown, 2006). In the long-delay group, the CS duration was $27 \mathrm{~s}$ and the ISI was $26 \mathrm{~s}$. In both groups, the mean intertrial interval (ITI) $( \pm$ SD) was $290 \pm 18 \mathrm{~s}$. Our working hypothesis predicted that scopolamine infusion into PR would impair trace but not long-delay conditioning.

Two short-delay groups (Fig. 1) were also included to evaluate further the task specificity of scopolamine-infusion effects. As noted previously, PR damage impairs short-delay conditioning to discontinuous tones (tone pips) but has no effect on short-delay conditioning to continuous tones (Lindquist et al., 2004; Kholodar-Smith et al., 2008a; Bang and Brown, 2009). In both short-delay groups, the CS duration was $15.6 \mathrm{~s}$, the ISI was $14.6 \mathrm{~s}$, and the mean ITI $( \pm$ SD) was $188 \pm 30 \mathrm{~s}$. The only difference between the two short-delay groups was that the CS in one group was a continuous tone and the CS in the other group consisted of a series of 21 tone segments (pips). The tone segments lasted $600 \mathrm{~ms}$ and the intersegment intervals lasted $150 \mathrm{~ms}$. Our working hypothesis predicted that scopolamine infusion would have no effect on either of the short-delay groups.

The auditory stimuli were presented free-field as described previously
(Bang and Brown, 2009). A heterodyne bat detector (Mini-3; Noldus Technology) transformed the ultrasonic stimuli into audible frequencies that enabled the experimenter to monitor cue presentations.

Surgery. Rats were anesthetized by injecting a mixture of ketamine $(100 \mathrm{mg} / \mathrm{kg})$ and xylazine $(10 \mathrm{mg} / \mathrm{kg})$. Next, they were secured in a stereotaxic instrument (Stoelting). The scalp was retracted and small burr holes were drilled bilaterally. A guide cannula (26 gauge; Plastics One) was lowered through each hole to the following coordinates: anteroposterior, $-5.0 \mathrm{~mm}$; mediolateral, $\pm 6.8 \mathrm{~mm}$; dorsoventral, $-7 \mathrm{~mm}$ relative to bregma (Paxinos and Watson, 2005). Dental cement (Stoelting) secured the cannulae in place. Animals recovered for at least $7 \mathrm{~d}$ before conditioning.

Conditioning and testing apparatus. Two rectangular Coulbourn chambers $(29 \mathrm{~cm}$ length $\times 25.5 \mathrm{~cm}$ width $\times 32 \mathrm{~cm}$ height $)$ were used for conditioning and testing. The chambers were located in sound attenuating enclosures that were housed in separate rooms. An infrared CCD camera (CB-21; Circuit Specialists) in each chamber was used to monitor and record behavior. One chamber (chamber A) was exclusively used for conditioning and context testing. The other (chamber B) was exclusively used for cue testing. Chamber A had a standard grid floor made of stainless-steel rods. The shock US was delivered to the grid by a shock generator (ENV-410; MED Associates) and grid scrambler (ENV-412; MED Associates). Chamber A was sprayed with white vinegar/water (1:3) solution before conditioning and context testing. During the experiment, both the inner chamber and the experimental room were illuminated. Chamber B had plastic flooring and was sprayed with Windex before cue testing. Both chamber $B$ and the experimental room were dark during cue testing.

Behavioral procedures. Twenty to $30 \mathrm{~min}$ before conditioning, subjects were infused with either normal saline $\left(0.9 \mathrm{~g}\right.$ of $\mathrm{NaCl}$ in $100 \mathrm{ml}$ of $\mathrm{dH}_{2} \mathrm{O}$, $\mathrm{pH}$ 7.4) or scopolamine hydrobromide $(10 \mathrm{mg} / \mathrm{ml}$; Sigma-Aldrich) dissolved in saline. During conditioning, all groups received 10 CS-US pairings in chamber A. Subjects were returned to their home cages $1 \mathrm{~min}$ after the last CS-US pairing. Cue and context conditioning were tested in counterbalanced order on the following $2 \mathrm{~d}$. During the cue test, rats received a 6 min presentation of the CS in a novel chamber (chamber B). The time course of conditional freezing was measured during three consecutive stages: a $2 \mathrm{~min}$ baseline period (before the cue CS was presented); a 6 min period of continuous CS presentation; and a 4 min post-CS period. During the context test, rats were placed in the original conditioning context (chamber A), in which they remained for 8 min. All experiments were recorded for off-line video analysis of freezing.

Cannula infusion. PR infusions, which were done in a separate preparation room, were made with a 33 gauge injector cannula (Plastics One) that extended $3.8 \mathrm{~mm}$ from the tip of the guide cannula. The infusion fluid $(1 \mu \mathrm{l})$ was delivered into each hemisphere at $0.5 \mu \mathrm{l} / \mathrm{min}$ via a syringe infusion pump (PHD 2000 Infusion; Harvard Apparatus). The fluid was infused via polyethylene tubing ( $0.38 \mathrm{~mm}$ diameter; Intramedic) that was attached to the infusion cannula on one end and to a $10 \mu \mathrm{l}$ Hamilton syringe (Hamilton) on the other end. The infusion cannula was left in place for $1 \mathrm{~min}$ after the fluid injection.

Histology. At the end of the experiment, rats were deeply anesthetized with an overdose of sodium pentobarbital (100 mg/kg, i.p.). Small marking lesions were made bilaterally by passing current between a wire inserted into a guide cannula and a ground wire ( $5 \mathrm{~s}, 100 \mu \mathrm{A}$ direct current; Lesion Maker; Grass Instruments). Transcardial perfusion with $0.01 \mathrm{M}$ PBS was followed by perfusion with $4 \%$ paraformaldehyde. The brain was then removed, placed in $4 \%$ paraformaldehyde for $24 \mathrm{~h}$, and cryoprotected in $30 \%$ sucrose for at least $2 \mathrm{~d}$. Each brain was serially sectioned in the coronal plane $(70 \mu \mathrm{m})$ using a freezing microtome. Finally, sections were mounted and Nissl-stained to verify cannulae placements.

Statistical analysis of freezing. Freezing behavior, the dependent variable, was measured using video-analysis software (Kholodar-Smith et al., 2008b). Freezing was defined as immobilization lasting $>3$ s. Each testing session was analyzed in $1 \mathrm{~min}$ time bins. The results were analyzed using a repeated-measures ANOVA (SPSS 14.0) with two between-subjects factors (type of infusion and conditioning procedure) and one withinsubjects factor (time bin). Where appropriate, ANOVA was followed by 
$t$ tests. The drug effect size was calculated using Cohen's $d$ statistic (Cohen, 1988).

\section{Results}

Verification of cannula placements

Figure 2 shows verified PR locations of the tips of the injection cannulae within PR in all subjects that were included in the behavioral analyses $(n=66)$. The tips were predominantly located in area 36, between 4.56 and $5.64 \mathrm{~mm}$ posterior to bregma (Paxinos and Watson, 2005). Four subjects were excluded because of misplacement of the cannulae. These included one subject in the scopolamine-infused short-delay tone group, two subjects in the scopolamine-infused short-delay pips group, and one subject in the saline-infused trace tone group. Five subjects were excluded because of failure to detect the marking lesions. These included two scopolamine-infused rats in the pips group, one in the salineinfused long-delay group, one in the saline-infused trace group, and one in the scopolamine-infused trace group. The number of remaining subjects in each of the four conditioning groups (Fig. 1) was as follows: short-delay tone, $n=16$; short-delay pips, $n=$ 16; long-delay tone, $n=16$; and trace tone, $n=18$. Within each conditioning group, the same number of animals (eight or nine) was in the scopolamine and vehicle conditions.

\section{Scopolamine effects on cue conditioning}

Figure 3 shows the time course of freezing behavior, in relationship to the presence of the auditory CS (shaded region), among scopolamine-infused animals (black circles) and saline-infused animals (white circles), in each of the four conditioning groups (Fig. 3A-D). Repeated-measures ANOVA revealed significant main effects of time interval $\left(F_{(11,638)}=110.87 ; p<0.005\right)$ and conditioning procedure $\left(F_{(3,58)}=4.09 ; p<0.05\right)$ as well as a significant interaction between the time interval and the conditioning procedure $\left(F_{(33,638)}=5.92 ; p<0.005\right)$. The main effect of $\operatorname{drug}\left(F_{(1,58)}=1.50 ; p>0.05\right)$ and the interaction between drug and time interval $\left(F_{(11,638)}=0.87 ; p>0.05\right)$ were not significant. However, there was a significant interaction between drug and conditioning procedure $\left(F_{(3,58)}=3.92 ; p<0.05\right)$, indicating that the drug effect depends on the conditioning procedure (Fig. 3 ). The triple interaction (time interval by conditioning procedure by type of infusion) was not significant $\left(F_{(33,638)}=1.09 ; p>\right.$ $0.05)$.

Contrasts between scopolamine- and saline-infused animals revealed a significant drug effect on trace conditioning, but no effect on delay conditioning. In trace conditioning, the mean $( \pm \mathrm{SE}$ ) level of freezing, tested during the $6 \mathrm{~min}$ CS presentation, was significantly lower among scopolamine-infused subjects $(21.8 \pm 11.2 \%)$ than among saline-infused subjects (58.7 \pm $\left.11.0 \% ; t_{(16)}=2.36 ; p<0.05\right)$. The overall drug effect size $(d)$ was 1.2. Cohen's rule of thumb (Cohen, 1988) is that "small," "medium," and "large" effect sizes correspond to $d=0.2,0.5$, and 0.8 , respectively.

In the long-delay conditioning group, which served as an ISIcontrol for the trace conditioning group (Fig. 1), there was no significant difference in freezing between scopolamine-infused subjects $(78.6 \pm 8.9 \%)$ and saline-infused subjects $(87.5 \pm 11.2$; $\left.t_{(14)}=0.63 ; p>0.05\right)$. Similarly, in the short-delay conditioning groups, there was no significant difference in freezing between scopolamine-infused animals (tone, $87.4 \pm 6.3 \%$; pips, $92.2 \pm$ $7.1 \%$ ) and saline-infused animals (tone, $84.2 \pm 8.0 \%$; pips, $82.4 \pm 10.3 \%$; tone, $t_{(14)}=0.31, p>0.05$; pips, $t_{(14)}=0.77, p>$ $0.05)$.

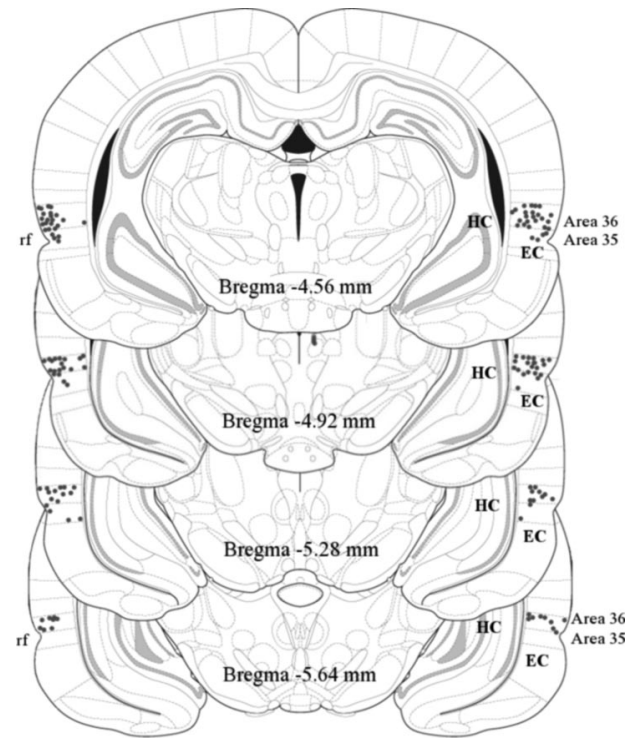

Figure 2. Distribution of verified cannula tips (small circles) among the 66 rats that were included in the analysis. Plate numbers are the distance posterior to bregma (Paxinos and Watson, 2005). Most tips were located closer to area 36 of rat PR, which is dorsal to the rhinal fissure (labeled rf), than to area 35 of PR, which is ventral to the fissure. EC, Entorhinal cortex; $H C$, hippocampus.

\section{Scopolamine effect on context conditioning}

Figure $4 A-D$ shows the time course of freezing, after being placed in the conditioning context (chamber A) (see Materials and Methods), among scopolamine-infused subjects (black circles) and saline-infused subjects (white circles) in all four conditioning procedures. ANOVA revealed a significant main effect of time interval $\left(F_{(7,406)}=7.12 ; p<0.005\right)$, but no effect of conditioning procedure $\left(F_{(3,58)}=0.81 ; p>0.05\right)$ or $\operatorname{drug}\left(F_{(1,58)}=0.44 ; p>\right.$ $0.05)$. There was a significant interaction between time interval and conditioning procedure $\left(F_{(21,406)}=2.04 ; p<0.05\right)$. The interactions between conditioning procedure and drug conditioning $\left(F_{(3,58)}=0.25 ; p>0.05\right)$ and between drug and time interval $\left(F_{(7,406)}=0.65 ; p>0.05\right)$ were both insignificant. The triple interaction (time interval by conditioning procedure by drug) was not significant $\left(F_{(21,406)}=1.00 ; p>0.05\right)$. All groups exhibited robust freezing to the conditioning context regardless of the type of infusion (Fig. 4). Whereas PR damage reliably and profoundly impairs context conditioning (Bucci et al., 2000; Lindquist et al., 2004; Kholodar-Smith et al., 2008a,b), the present results show that $\mathrm{mAChR}$ function within $\mathrm{PR}$ is unrelated to this deficit.

\section{Discussion}

\section{Brief summary}

Pretraining scopolamine infusions into PR profoundly impaired trace conditioning (Fig. 3D) but did not impair delay conditioning to a continuous tone (Fig. $3 C$ ). Both of these outcomes match the effect of pretraining PR lesions. However, unlike PR lesion effects, scopolamine infusions had no effect on delay conditioning to a discontinuous tone (Fig. 3B) and no effect on context conditioning (Fig. 4). These findings suggest that the drug infusion did not cause general PR dysfunction. Of the three major effects of PR lesions on acquired fear, described previously, only trace conditioning seems to depend on mAChR function. This pattern of results was predicted by the hypothesis (Leung et al., 2006; Hasselmo et al., 2007; Kholodar-Smith et al., 2008b) that persistent firing enables trace conditioning. 

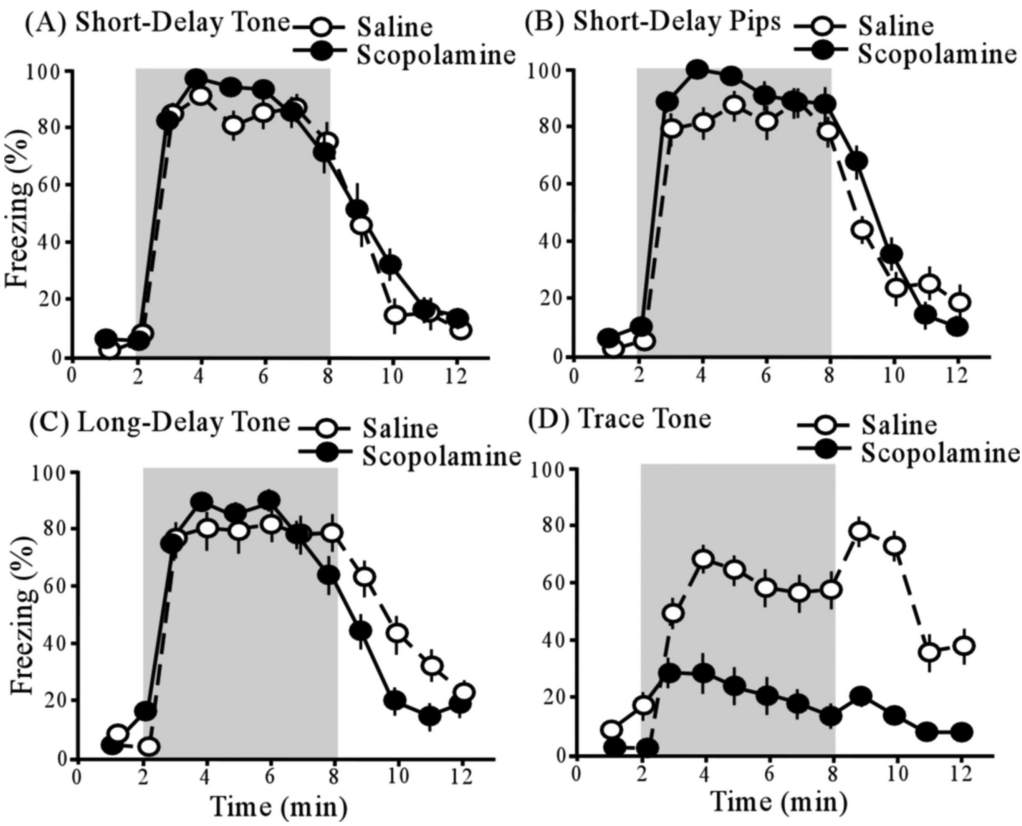

Figure 3. Cue tests after each of four fear conditioning procedures. Light shading represents the $6 \mathrm{~min} C S$ presentation period. Pairs of plots show the time course of freezing in saline-infused animals (open circles) and scopolamine-infused animals (filled circles). $\boldsymbol{A}$, Time course of freezing in the short-delay tone group. $\boldsymbol{B}$, Time course of freezing in the short-delay pips group. $\boldsymbol{C}$, Time course of freezing in the long-delay tone group. $\boldsymbol{D}$, Time course of freezing in the trace-tone group. The only significant effect of scopolamine was in the trace-tone group. The increase in freezing after the $C S$ offset has been previously observed (Moyer and Brown, 2006; Boguszewski et al., 2008). Error bars indicate SEM.
(A) Short-Delay Tone

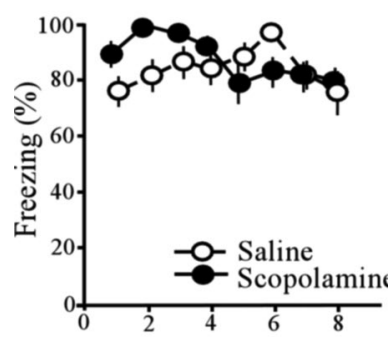

(C) Long-Delay Tone

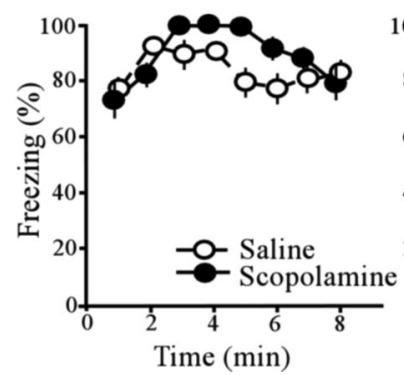

(B) Short-Delay Pips

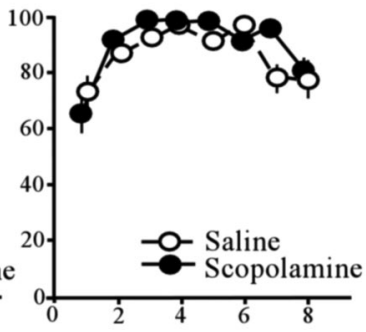

(D) Trace Tone

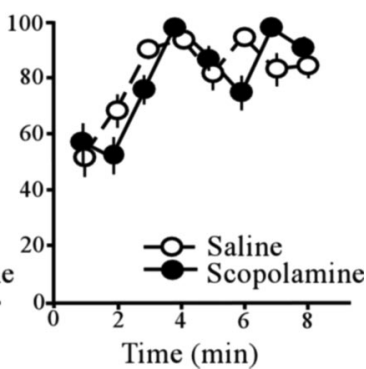

Figure 4. Freezing to the conditioning context testing in the four cue-conditioning groups. $\boldsymbol{A}$, Time course of freezing in the short-delay tone group. $\boldsymbol{B}$, Time course of freezing in the short-delay pips group. $\boldsymbol{C}$, Time course of freezing in the long-delay tone group. $\boldsymbol{D}$, Time course of freezing in the trace-tone group. Scopolamine had no significant effect on context conditioning in any of the four cue-conditioning groups. Error bars indicate SEM.

\section{Localization of scopolamine effects}

Although the injection sites were all within PR (Fig. 2), the actual spread of scopolamine around the injection site is uncertain. One major concern was drug diffusion to the amygdala. PF neurons are prevalent in LA (Egorov et al., 2006), which in turn is well known for its essential role in acquired fear (Maren and Quirk,
2004; Rodrigues et al., 2004). To minimize the likelihood of drug spread to LA, none of the injection sites was in the anterior portion of PR that is laterally adjacent to LA (Fig. 2). Nevertheless, it will be interesting and important to explore the effects on trace fear conditioning of scopolamine injections that specifically target LA. Since PR and LA have strong reciprocal connections (Furtak et al., 2007), it may turn out that transient CS representations depend on networks of PF neurons in both PR and LA.

Another potential concern was drug spread to EC (Fig. 2), where PF neurons are also prevalent (Egorov et al., 2002; Fransén et al., 2006; Reboreda et al., 2007; Tahvildari et al., 2007, 2008). To minimize this possibility, we attempted to target dorsal PR (area 36, above the rhinal fissure) (Fig. 2). There have been no studies of the effects of scopolamine injections into EC on trace fear conditioning. Similarly, there have been no studies of the effects of EC damage on trace fear conditioning. However, EC damage has been shown to impair eyeblink conditioning using a short-trace interval (550 ms) (Ryou et al., 2001). The reciprocal connections between PR and EC (Furtak et al., 2007) raise the possibility that these two structures may also function together as part of a transient memory network (Schon et al., 2005).

A final concern was drug spread to the hippocampus (Fig. 2), where cholinergically controlled conductances have also been described (Johnston and Amaral, 2004). In contrast with the present findings, scopolamine infusion into the hippocampus significantly impairs context conditioning (Gale et al., 2001; Wallenstein and Vago, 2001). Hippocampal damage is well known to impair trace conditioning (McEchron and Disterhoft, 1999; Shors, 2004; Thompson, 2005). There is no evidence regarding the effects of hippocampal infusions with scopolamine on trace fear conditioning.

Systemically administered scopolamine also impairs trace but not delay fear conditioning (Anagnostaras et al., 1995; Kaneko and Thompson, 1997; Hunt and Richardson, 2007) (but see Rudy, 1996). In this respect, the effect of infusing PR with scopolamine matches the effect of systemically administered scopolamine, which also matches the effect of PR damage. Systemically administered scopolamine is also known to impair context conditioning (Anagnostaras et al., 1995; Rudy, 1996). This effect matches the consequence of PR lesions but does not depend on muscarinic receptors in PR (Fig. 4). The simplest interpretation of the facts is that mAChRs within PR selectively control trace fear conditioning.

\section{Some broader implications}

The present findings encourage parallel investigations of scopolamine infusions into EC, LA, and the hippocampus. As suggested above, it may turn out that trace fear conditioning depends on $\mathrm{mAChR}$-dependent mechanisms that are distributed among PR and nearby structures. Since persistent firing strictly depends on ACh levels, it is natural to wonder what controls ACh release. One 
possibility is that projections from prefrontal cortex to cholinergic neurons in the basal forebrain (Sarter et al., 2005; Egorov et al., 2006) ultimately control ACh release onto PF neurons in PR. The present results encourage additional investigation into the emerging theory that PF neurons support aspects of transient memory in a group of interconnected medial-temporal-lobe structures.

\section{References}

Anagnostaras SG, Maren S, Fanselow MS (1995) Scopolamine selectively disrupts the acquisition of contextual fear conditioning in rats. Neurobiol Learn Memory 64:191-194.

Bang S, Brown TH (2009) Perirhinal cortex supports acquired fear of auditory objects. Neurobiol Learn Mem. Advance online publication. Retrieved March 13, 2009. doi:10.1016/j.nlm.2009.01.002.

Beylin AV, Gandhi CC, Wood GE, Talk AC, Matzel LD, Shors TJ (2001) The role of the hippocampus in trace conditioning: temporal discontinuity or task difficulty? Neurobiol Learn Mem 76:447-461.

Boguszewski P, Allen TA, Brown TH (2008) CS-offset encoding in auditory fear conditioning. Soc Neurosci Abstr 34:93.5.

Bucci DJ, Phillips RG, Burwell RD (2000) Contributions of postrhinal and perirhinal cortex to contextual information processing. Behav Neurosci 114:882-894.

Cohen J (1988) Statistical power analysis for the behavioral sciences. Hillsdale, NJ: Erlbaum.

Egorov AV, Hamam BN, Fransén E, Hasselmo ME, Alonso AA (2002) Graded persistent activity in entorhinal cortex neurons. Nature 420:173-178.

Egorov AV, Unsicker K, von Bohlen und Halbach O (2006) Muscarinic control of graded persistent activity in lateral amygdala neurons. Eur J Neurosci 24:3183-3194.

Fransén E, Alonso AA, Hasselmo ME (2002) Simulations of the role of the muscarinic-activated calcium-sensitive nonspecific cation current $I_{\mathrm{NCM}}$ in entorhinal neuronal activity during delayed matching tasks. J Neurosci 22:1081-1097.

Fransén E, Tahvildari B, Egorov AV, Hasselmo ME, Alonso AA (2006) Mechanism of graded persistent cellular activity of entorhinal cortex layer V neurons. Neuron 49:735-746.

Furtak SC, Wei SM, Agster KL, Burwell RD (2007) Functional neuroanatomy of the parahippocampal region in the rat: the perirhinal and postrhinal cortices. Hippocampus 17:709-722.

Gale GD, Anagnostaras SG, Fanselow MS (2001) Cholinergic modulation of Pavlovian fear conditioning: effects of intrahippocampal scopolamine infusion. Hippocampus 11:371-376.

Hasselmo ME (2008) Temporally structured relay of neural activity in a model of entorhinal cortex, hippocampus and postsubiculum. Eur J Neurosci 28:1301-1315.

Hasselmo ME, Stern CE (2006) Mechanisms underlying working memory for novel information. Trends Cogn Sci 10:487-493.

Hasselmo ME, Giocomo LM, Zilli EA (2007) Grid cell firing may arise from interference of theta frequency membrane potential oscillations in single neurons. Hippocampus 17:1252-1271.

Hunt PS, Richardson R (2007) Pharmacological dissociation of trace and long-delay fear conditioning in young rats. Neurobiol Learn Mem 87:86-92.

Johnston D, Amaral DG (2004) Hippocampus. In: The synaptic organization of the brain (Shepherd GM, ed), pp 455-498. New York: Oxford UP.

Kaneko T, Thompson RF (1997) Disruption of trace conditioning of the nictitating membrane response in rabbits by central cholinergic blockade. Psychopharmacology 131:161-166.

Kholodar-Smith DB, Allen TA, Brown TH (2008a) Fear conditioning to discontinuous auditory cues requires perirhinal cortical function. Behav Neurosci 122:1178-1185.

Kholodar-Smith DB, Boguszewski P, Brown TH (2008b) Auditory trace fear conditioning requires perirhinal cortex. Neurobiol Learn Mem 90:537-543.

Leung VL, Zhao Y, Brown TH (2006) Graded persistent firing in neurons of rat perirhinal cortex. Soc Neurosci Abstr 32:636.18.

Lindquist DH, Jarrard LE, Brown TH (2004) Perirhinal cortex supports delay fear conditioning to rat ultrasonic social signals. J Neurosci 24:3610-3617.

Maren S, Quirk GJ (2004) Neuronal signalling of fear memory. Nat Rev Neurosci 5:844-852.

McEchron MD, Disterhoft JF (1999) Hippocampal encoding of non-spatial trace conditioning. Hippocampus 9:385-396.

Moyer JR Jr, Brown TH (2006) Impaired trace and contextual fear conditioning in aged rats. Behav Neurosci 120:612-624.

Murray EA, Bussey TJ, Saksida LM (2007) Visual perception and memory: a new view of medial temporal lobe function in primates and rodents. Annu Rev Neurosci 30:99-122.

Paxinos G, Watson C (2005) The rat brain in stereotaxic coordinates-the new coronal set, Ed 5. Sydney: Academic.

Reboreda A, Raouf R, Alonso A, Seguéla P (2007) Development of cholinergic modulation and graded persistent activity in layer $\mathrm{V}$ of medial entorhinal cortex. J Neurophysiol 97:3937-3947.

Rodrigues SM, Schafe GE, LeDoux JE (2004) Molecular mechanisms underlying emotional learning and memory in the lateral amygdala. Neuron 44:75-91.

Rudy JW (1996) Scopolamine administered before and after training impairs both contextual and auditory-cue fear conditioning. Neurobiol Learn Mem 65:73-81.

Ryou JW, Cho SY, Kim HT (2001) Lesions of the entorhinal cortex impair acquisition of hippocampal-dependent trace conditioning. Neurobiol Learn Mem 75:121-127.

Sarter M, Hasselmo ME, Bruno JP, Givens B (2005) Unraveling the attentional functions of cortical cholinergic inputs: interactions between signal-driven and cognitive modulation of signal detection. Brain Res Brain Res Rev 48:98-111.

Schon K, Atri A, Hasselmo ME, Tricarico MD, LoPresti ML, Stern CE (2005) Scopolamine reduces persistent activity related to long-term encoding in the parahippocampal gyrus during delayed matching in humans. J Neurosci 25:9112-9123.

Shors TJ (2004) Memory traces of trace memories: neurogenesis, synaptogenesis and awareness. Trends Neurosci 27:250-256.

Tahvildari B, Fransén E, Alonso AA, Hasselmo ME (2007) Switching between "On" and "Off" states of persistent activity in lateral entorhinal layer III neurons. Hippocampus 17:257-263.

Tahvildari B, Alonso AA, Bourque CW (2008) Ionic basis of ON and OFF persistent activity in layer III lateral entorhinal cortical principal neurons. J Neurophysiol 99:2006-2011.

Thompson RF (2005) In search of memory traces. Annu Rev Psychol 56:1-23.

Wallenstein GV, Vago DR (2001) Intrahippocampal scopolamine impairs both acquisition and consolidation of contextual fear conditioning. Neurobiol Learn Mem 75:245-252.

Woodruff-Pak DS, Disterhoft JF (2008) Where is the trace in trace conditioning? Trends Neurosci 31:105-112. 